\title{
THE ROLE OF AUTOMOBILE SECTOR IN GLOBAL BUSINESS: CASE OF PAKISTAN
}

\author{
Irfan Ul Haque \\ Ph.D Scholar \\ Greenwich University \\ Karachi-Pakistan \\ irfan3323@gmail.com \\ Dr. Aamir Rashid \\ Associate Professor \\ Head of Business Administration \\ Greenwich University \\ Karachi-Pakistan \\ qaboola10@yahoo.com \\ Dr. Syed Zubair Ahmed \\ Member Board, Islamabad Chapter \\ Association of Certified Fraud Examiner, Inc. USA \\ syedzubairahmed@rocketmail.com
}

\begin{abstract}
The global automobile sector is among the driving forces of worldwide economies. Similarly in Pakistan, the automobile sector is the one of greatest industries. Although the automobile is one of the leading private sectors in Pakistan, the industry is largely protected from the external race. Over the eras, the automotive manufacturing consumes made a known run-of-the-mill presentation in rapports of continual and continuous progress. The vehicle manufacturing of Pakistan ensures not to partake a noteworthy part in the overall additional worth of the industrial segment. This study is finding out the effects of high duties, production, technology, and government policies on automobile growth in Pakistan. It will contribute to other important factors that affect the growth of the Automobile Industry worldwide and specially in Pakistan. Many studies
\end{abstract}


The Role of Automobile Sector in Global ...

use the Balassa index to analyse comparative global trade benefits, which have been shown (particularly in agriculture), but the selected automotive industry has novel study possibilities. This research focuses on the competitiveness of the car industry, a crucial sector because of its high added value, competitive market, growing technical demands and a high level of employment. The objective of our article is to analyse the comparative benefits indicated by Markov's transition probability and the caplan-meier survival function of the global car trade, and the duration and stability of the Balassa indices. Data sources for 1997-2016 are worldwide HS6 car shipments. The article has arrived at several findings. Initially, analysing the global vehicle trade, it was found that the USA, China, Germany and Japan were the greatest vehicle manufacturers, but in the time examined, the main exporters were Germany, Japan and Canada, collectively accounting for $40 \%$ of all goods shipped, with $71 \%$ of the top 10 nations. Second, the most traded/exported automotive product, as we analysed it, was a worldwide vehicle with just dazzling internal ignition (1500-300cm 3) (870323), representing more than $40 \%$ of the whole 1997-2016 export of vehicles. Third, the Balassa calculations reveal that in every period evaluated by the most prominent automotive exporters in the world, Spain and Japan had the largest comparative advantages. This is a descriptive correlational study and the primary purpose is to examine variables and relationships. This study is conducted in the education sector in Karachi, Pakistan with four variables to investigate the causal relationship among different variables. This study constructed a conceptual framework to illustrate a causal relationship by defining the relevant variables. It indicates the independent variable (the cause) and the dependent variable (the effect). There is a positive relationship between production and automobile growth. The effects of Duties are 0.294 on automobile growth and the effect of government policy is 0.177 on automobile growth and the effect of production is 0.152 on automobile growth and the effect of technology is 0.150 .

Keywords: Automobiles, Automotive industries, industrial sectors, economic growth 


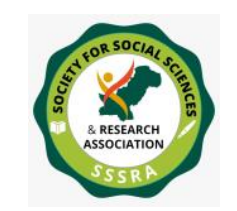

Pak. Journal of Int'L Affairs, Vol 4, Issue 2 (2021)

The Role of Automobile Sector in Global ...

\section{Introduction}

Vehicle manufacturing is amid the limited manufacturing which has attracted native and extraneous funds to level the asset macroclimate in the country has not been congenial. Moreover, it is not developed as much that comes to a noticeable list of the top automobile industries. Due to less technology in Pakistan, technology and production have an invariable impact on automobile growth. New automobile technological advancement throughout the world, in addition to revolution determination turns out to be a foremost lashing strength cutting-edge of automobile area enlargement.

The Pakistani industrial sector has more segmented \& one of the vital industrial sectors is based on vehicle manufacturing or services which are known as vehicle manufacturing. In the large gauge developed trade an Auto Vehicle manufacturing is a pouring potency and significant portion of the manufacturing possessions of Pakistan. Historical facts and figure are as manufacturing was happening after General Motors and Sales Firm remained recognized in 1949. Bedford truck stood is the initial vehicle, which stood accumulated vogueish the republic. Subsequently that, numerous further organizations arrived or cross the threshold the marketplace besides manufacturing grew swiftly throughout the renationalization era. During the 1970s, manufacturing remained stateowned sideways through numerous engineering manufacturing businesses. Nevertheless, they acquire the vital industry era that proved an upright era for the automobile segment, the scope of public-sector creativities extended to an uncontrollable degree.

Consequently, near the era of denationalization, for the duration of the administration of General Zia-ul-Haq (R), the progression of sale happens after countrywide management flogs a plus or job toward sequestered stockholders in addition to de-directive ongoing. Even though the hard work is situated further absorbed in the direction of party-political paybacks, they unlocked the gate aimed at external speculation and liberalization of the manufacturing segment. Throughout the 1990s, the denationalization development ongoing, and eight on the view of fifteen auto parts be situated vended obtainable towards the set apart segment. That de-nationalization conveyed roughly many positive also opposing active in addition non-active or fluffs pioneering the auto industrial engineering. The strategies of the Gov. Administration unprotected the manufacturing toward exposed marketplace struggle as soon as it permissible nil-valued importation of taxi-car underneath of umbrella of the scheme of Yellow-Cab. As a result, the income of cars weakened radically from 65,000 for each year to 45,000 items per year.

The optimistic part of denationalization is situated at the entrance of overseas companies. The manufacturing resisted a portion throughout 1995-2000. Though, the post-2000 set- 


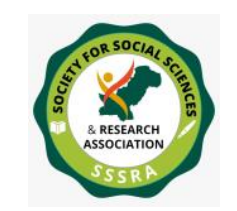

The Role of Automobile Sector in Global ...

up be situated decent by way of the segment became countless subsidiary influences toward improvement up and about the manufacturing industries. These issues comprised the obtainability of car sponsorship, increase the cutting-edge overseas transfer of funds, quick financial development, in addition, the hard work thru using the administration management means the government of Pakistan. The manufacturing veteran an identical great progress amount on or after 2001 towards 2005. Though, the development method stood intermittent using the close-fitting regulatory financial procedure, party-political uncertainty, and a weakening cutting-edge home-based transmittals.

This study is aimed to find out the growth of the Automobile sector of Pakistan. There is a significant decline in the automobile sector because of some variables, such as high duties, government policies, lack of technology, and production. The main objectives are to investigate the impact of high duties, production, technology, and government policies on automobile growth in Pakistan and to collaborate with the relevant literature to provide a further base for future research.

The current study also aims to find the answer to the some questions: How to determine the relationship and impact of associated variables such as high duties, production, technology, and government policies on automobile growth in Pakistan, and does the observed relationship among variables and its implications consistent with economic development. The scope of the study is to know the reasons why the automobile sector of Pakistan has fallen into bad shape and has reduced the industry's growth.

\section{Theoretical Framework}

For a long time, different companies have tried to incorporate electric cars into the market. First viable attempts date from 1884. Some initiatives in Brazil like "Itaipu E150" that dates back to 1981. The main advantages of electric cars are: significant reduction to audible noise, high torque in low speeds, regenerative braking (deceleration energy can be recovered instead of consumed as heat), low maintenance (electric motors are sturdy, basically main wear is related to bearings) and energy may come from any resource used to generate energy, hence it can be considered capable to use renewable energy sources.

The main limitation considering technology is energy storage density. Compared to IC engines, the energy density in the electric car is significantly smaller, which leads to shorter ranges on electric car solutions. Main automotive companies already envision the trend and are making hybrid cars more and more popular, to balance range and improve 


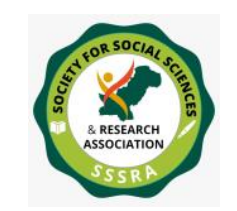

The Role of Automobile Sector in Global ...

efficiency. Chevy Volt is a relevant example, since it started with a concept of a pure electrical vehicle (concerning power-train) and later evolved into a connection between electric and IC engines, like a hybrid. It acquires a great balance on efficiency, performance, and range, using a motor/generator concept to a deep utilization and a small IC engine as a battery charger/traction booster. Now other hybrid cars use a similar concept.

The next key leap required is on battery technology, to increase energy storage density, reliability, safety, and cost. Today's technology still presents heavy, temperaturesensitive, short life, and flammable electrolytes as downsides for batteries.

The vision has raised the demand for a major transformation in how we see and handle cars in the future. Roads with wireless electric chargers would eliminate battery demand and provide us with a mobile solution that is significantly superior to IC engines. It is similar to electric busses or trains, just on a smaller scale for the user and a major infrastructure scale on the roads. Autonomous cars would largely benefit from this. It would be much simpler and safer to have smart roads, which could use transponders as planes to avoid collision and manage traffic. For all this, no major technology leap is required, but government incentives to turn it into reality.

\section{Research Methodology}

To investigate the impact of the relationship of duties, production, technology, and government policies with automobile growth in Pakistan. A questionnaire survey was conducted through email. The sample for this study comprises automobile consumers in Pakistan. The following research method was employed in this research. Primary data was conducted through a survey consisting of 19 questions that were distributed through email. The 110 questionnaires were distributed through emails, and wherein a sample of 98 questionnaires was available. All were based on the five facts Comparable measure someplace five signify powerfully come to an understanding and one exemplifies disagree- strongly out of hundred, among the respondents 63 were male and 35 were female.

This study is limited to automobile growth in Pakistan, and only four factors have been studied (government policy, taxes, productivity, and technology) about the impact on the Automobile industry growth. Also, it is a quantitative study, in the future this subject can be studied with a mixed or qualitative approach.

\section{Significance of the Industry for Macroeconomic Activity and International Trade}




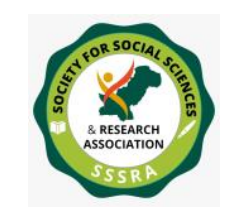

The Role of Automobile Sector in Global ...

The motorized manufacturing consumes a distinct abode cutting-edge the complete budget, predominantly cutting-edge manufacturing republics. Aimed at the sample, the auto vehicle stands another solitary toward a household cutting-edge acquisition worth aimed at the run-of-the-mill American domestic. The regular industrial occupation cutting-edge the motorized segment wages 60 out of a hundred further than the regular U.S. profession. It stands projected that the manufacturing makes 10.4 occupations intended for every single employee straight working cutting-edge auto industrial and provision facilities (exclusive of auto traders) cutting-edge the United States. Profession spillovers continue to assume cutting-edge manufacturing besides non - engineering trades, as well as merchandising employment and facilities. In 2000, motorized automobiles and gear (assemblers and dealers) expense happening investigation and growth $(R \& D)$ outstripped $R \& D$ expenditure cutting-edge numerous of the 39 major manufacturing clusters, together with medicines and drugs, semiconductors and further electrical mechanisms, infrastructures gear, and workstations and outlying gear. Motorpowered automobiles remain similarly the main constituent of worldwide jobs and overseas straight speculation among republics.

In 2000, the portion of motorized goods in domain skill was 9.4 out of a hundred, unaffected on or after its segment a period prior. Asia, N. America, and West Europe in deteriorating instruction stand the worldwide influential in carry across and ingresses. Although West E.U. and Asia are remaining exporters of automobiles, North American ingresses remote outstrip spreads. In N. America, spreads consume continued comparatively level subsequently the 1980s, while ingresses consume step up. N. America, East E.U., the Middle East, and Africa are entirely remaining traders of motorized produces. Intraregional trade statistics display that intra-western European trade remained the major in worth next to more or less US\$200 billion that time, intraNorth American trade remained $2^{\text {nd }}$ by the side of US $\$ 87.7$ billion, and intra-Asian trade was the bottom by the side of US\$19.6 billion. Interestingly, intra-American trade declined by 10 out of a hundred directly connected in the 1990s. North America's exchange with its European and Latin American allies was the fastest-growing region-toregion trade.

From time to time, obstacles have been erected across the globe to guard the global automotive industry. Designed for specimen, above the previous 21 years, republics in North America and Europe take established pricelist and non-tariff fences exactly functional to a vocation in autos industries. Between 1981 and 1988, the United States and Japan "voluntarily" settled happening an immovable number of vehicle parts that Japan would export to the United States. The European Union and Japan similarly move in an unpaid spread contract (VER) between 1990 and 1999, as Japanese imports to 


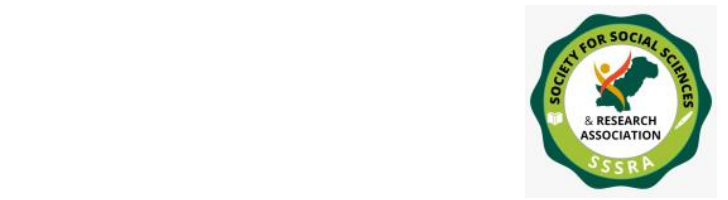

The Role of Automobile Sector in Global ...

Europe started to outpouring. In both cases, the VERs be situated somewhat accountable on behalf of a rise in relocating making, as Japanese auto manufacturers jumped above the skill barriers to straight industrial facilities in the U.S. and E.U.

Even though the relocates consume develop a precarious constituent of the native industrial countryside, the occupations and disseminates that they produce are prejudiced in contradiction of their reducing consequence happening salaries and the charges that approximately native governments experience to fascinate overseas businesses toward their area. In emerging states, skill, and speculation limits cutting-edge the motorized segment income the procedure of native gratified rubrics, prices, and shares. The motivation behindhand these protective actions stands toward stretch native makers an accidental to grow beforehand they express rivalry on or after superlative automobile manufacturers that stand additional creative and consequently consume inferior component prices. Cutting-edge current periods, local skill promises consume remained applied that relax numerous of these native gratified, speculation, and vocation limitations. The North American Free Trade Agreement (NAFTA), which was applied in 1994, be situated unique important sample. Once the United States and Canada comprised Mexico popular their permitted job deal happening service cutting-edge autos and fragments, Mexico summary prices aimed at its northerly associates and raised limits on native speculation aimed at all external businesses, permitting national position aimed at remove processes. Unique of the dangerous elements of the position of get-together shrubberies and their connected dealers is manufacture price.

Manufacture charges and marketplace chances are the main motives why occupations are fluctuating absent after the old-style topographical hubs of automobile manufacture. In a similar period, the application of the trim manufacture example is instable the working middle of automobile manufacture in the direction of first-tier providers with worldwide competencies. Flexible prices of manufacture-prices that be contingent happening the number of cars formed- comprise expenses on resources and employment. In motorized manufacturing, quantifiable prices variety between 22 and 50 out of a hundred, while manual labor budgets assortment from 10 to 20 out of a hundred. Since these prices differ by area and creation shaped, car assemblers and dealers are aggressively betrothed in valuations and alteration procedures that principal to vicissitudes in the shape and processes of their plant life. Up till now, the development of North American, European, Asian, and South American interchange coalitions has important insinuations for the environmental shape of manufacture and job streams. Whereas it leftovers a significant aspect, the qualified benefit is not the only factor of job designs in motorized manufacturing. 


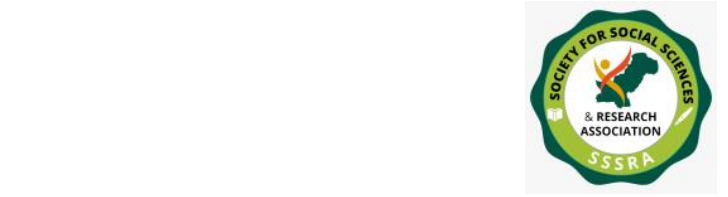

Pak. Journal of Int'L Affairs, Vol 4, Issue 2 (2021)

The Role of Automobile Sector in Global ...

\section{Literature Review}

A country's economy flourishes when its local manufacturing industry grows and the main focus of any government is to make its local industry stand on its feet and driven by mobilizing domestic resources. Unfortunately, the automobile sector does not show steady growth, it indicated a sudden upward trend and after some time the graph of growth has been downward sloping.

Given the state-owned manufacturing segment that Pakistan congenital on the spell of freedom, the auto manufacturing consumes grownup through bounds and limits cuttingedge additional than semi an era. Substantial growing and volume were industrialized cutting-edge the preschooler phases as soon as the manufacturing was first usual active below government direction and provision, nonetheless, technical expertise and competitiveness consume escaped the manufacturing aimed at the greatest share however a trickle of companies consume achieved toward attaining an amount of worldwide and developing local technological capabilities considerably cutting-edge footings of nearby intended and shaped mechanisms, shares and goods.

Currently, effectiveness container remain attained cutting-edge late-night emerging republics such by way of Pakistan, finished a procedure of wisdom and competition, slightly than a novelty, the developing agreement by academics such as Bell and Pavitt (1997) and Amsden (1989), is that emerging republics canister improvement concluded knowledge and mock. The automobile industrial add-ons and leftovers affected finished frequent variables, on the other hand, replicates by way of rapidly using intent happening innate industry - administration management protocols, farm duties in infrequent computable and production and practical development trace the supreme.

The auto manufacturing of Pakistan prepares not to consume a foremost part cutting-edge entire worth additional cutting-edge the industrial segment that difference fits toward the dual groups of fabrics and nourishment, drinks, and tobacco, together of which are deeply at the compassion of happening the agrarian subdivision for rare constituents, and which motionless explanation aimed at ended 50\% appreciated additional in industry. But after all these circumstances the automotive segment still achieves to brand a significant influence on the national budget in footings of service, income, and external conversation age groups, not to reference human reserve growth. The yearly income for manufacturing is more than PKR 30 billion, though it donates fewer than 3\% to GDP.

With the help of a literature review, it is considered up to some extent that many factors can affect the growth of the automobile sector in Pakistan. These factors may vary with 


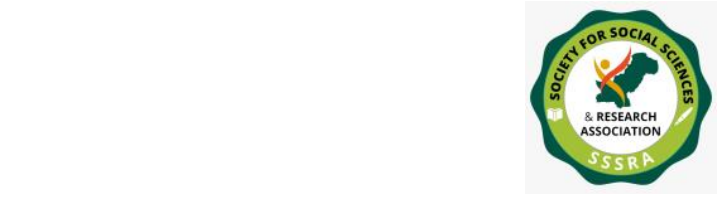

The Role of Automobile Sector in Global ...

the change in geographical, sociological, and other environmental factors. Because of different assumptions and perceptions, bounding with liabilities are also different from each of the above-listed approach. Therefore, they are correlated with everyone under the circumstances of automobile growth. Each of the above-listed approaches has its advantages and disadvantages. Some criticism also exists and its effects are negligible on the factors of automobile growth. As the main objective of this study is to know whether the identified factors affect automobile growth or not.

\section{Variables of the study}

The configuration of the variables of the learning remains using:-

\section{Automobile growth:}

Above the periods, the auto manufacturing consumes demonstrated a regular presentation of cutting-edge rapports of maintainable and determined development. Statistics happening manufacture cutting-edge the auto manufacturing remains obtainable aimed at the era since 1974 towards 75 to period and expressions that the manufacturing's routine guzzles remained the uppermost throughout the 1970s besides at that time over throughout the 2000s. Enactment deteriorated cutting-edge the 1980s in addition clear-cut additional cutting-edge the 1990s to a smaller amount than 4 out of a hundred throughout the 1990s. The on or after highest to lowest growth counted front-line the preceding 4 to 5 years consumes typically remain located expected credit towards the state's business outward-bound policies end-to-end through inferior pricelist duties, unceasing development of GDP, in addition, each capita revenue, although the original upsurge is greatest probable happening clarification of the huge speculation assumed throughout the developing ages as soon as the republic's manufacturing dishonorable remained existence recognized on or after scrape.

The Auto manufacturing consumes remained a lively and rising manufacturing cuttingedge of Pakistan aimed at an extended period, though not as ample recognized toward originate cutting-edge the obvious slant of the highest auto trades. Manufacture capacity consumes sustained augmented cutting-edge auto manufacturing but transmission or skill leftovers small. The auto segment achieves its purpose underneath the permit and practical collaboration contracts through European, Korean and Japanese, producers.

By way of the manufacture remains founded happening external combined undertakings thus the worldwide principles remain shadowed cutting-edge the produces. Auto 


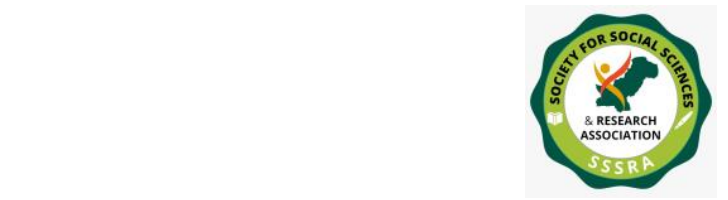

The Role of Automobile Sector in Global ...

manufacturing remains amongst the insufficient trades which are enticing native and overseas funds smooth the asset environment cutting-edge the manufacturing remains not respectable. The automobile manufacturing forecast a rising demand in Pakistan and participated ended Rs 20 billion throughout this period. Motorcycle manufacture success a top side by side in 2016-17, through 2.5 million components completed.

In 2015, the Automobile Strategy 2016-21 remained to bring together,_towards assistance trap new-fangled automakers, which consumes conventionally remained conquered through Honda, Toyota, and Suzuki. The automobile manufacturing remnants the $2^{\text {nd }}$ major customer of unintended duties afterward the fuel business in Pakistan. There are currently 10 cars for every 1,000 persons in Pakistan. This is one of the lowest ratios in emerging economies, which stands for itself of the high growth potential, increasing per capita income, with a shifting demographic distribution and an expected influx of 30 to 40 million young people into economically active labor force over the next decade, would usher in an opportunity for the industry to develop and grow. Toyota began the local assembly of its Corolla sedan. Likewise, United Motors launched its first locally manufactured Pakistani vehicle. Ghandhara Nissan has started the production of Isuzu dmax in Pakistan.

By the side of the current, the automobile marketplace remains conquered through Honda, Toyota, and Suzuki. Though, on 19 March 2016, Pakistan approved the "Auto Strategy 2016-21, which suggestions toll inducements toward new-fangled automakers toward found industrial facilities in the republic. In response, Renault, Nissan, Proton, Kia, SsangYong, Volkswagen, FAW, and Hyundai consume articulated attention in incoming the Pakistani marketplace. NLC contracted a contract through Mercedes Benz aimed at the industrial of Mercedes cars in Pakistan.

\section{Production:}

The main purpose of the automobile industry is to produce and sell automotive products to its customers. Production comes in two phases one is producing parts and the second part is producing a vehicle that assembles the whole vehicle using those parts. But the main concern is that in Pakistan the companies which are manufacturing or assembling the cars are importing parts and just doing the assembling process. This increases the price of final output and it goes beyond the pockets of many customers.

While on the other hand after-sales parts are manufacturing in Pakistan and considered as of good quality. While the bikes are manufacturing in Pakistan with their OEM auto- 


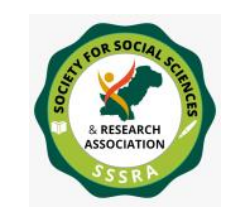

Pak. Journal of Int'L Affairs, Vol 4, Issue 2 (2021)

The Role of Automobile Sector in Global ...

parts. Some other vendors are also working on the manufacturing of bikes after-sales parts. Tractors are also manufacturing in Pakistan. The local manufacturing plants are establishing that consider as a positive sign for the growth of the automobile industry.

\section{Technology:}

Technological advancement in every sector is increasing day by day. With every new model, customer demands some new features or technology. Unfortunately, Pakistan's automobile sector is not in line with global technological advancement. The main reason for this is that we are not pursuing locally for up-gradation. The technology develops by the world while adoption increases the price of the final product.

By the side of the comprehensive international side by side, close through be situated apparent benefits of technical associations that are attractive residence altogether above the domain of countries of the globe. Technologically advanced in addition evolving republics opinion toward improvement on or after lawmaking and financial improvements. Skill transmission remains here and now attractive abode cutting-edge Pakistan using a system of government on or after numerous established republics. Technology advancement is required not only in the automobile sector but everywhere in the manufacturing industry. When there is updated technology available in local manufacture cars the demand increases and industry flourishes.

The local automobile industry is complex cutting-edge expertise transmission straight toward indigenous salespersons concluded fragments, sketches, in addition, procedure pieces. Substructure in addition engineering competence is examined initially in the direction of the magistrate the possibility of a native purveyor beforehand authorizing him toward being responsible for a model of the creation intended for analysis/ endorsement. Japanese keep on equipped in the direction of delivering technical support up and around in the direction of a convinced stage, nonetheless motionless not at all satisfactory organization, in addition, accomplished all sort of the workforce have been present grown towards come across the preferred principles.

On run-of-the-mill solitary $45 \%$ of portions of numerous mockups consume remained allowable toward be situated industrialized in the vicinity through any manufacturing firm subsequently their wide-ranging assessment courts-martial cutting-edge Japan. Owing in the direction of the non-availability of costly excellence switch apparatus, altogether meticulousness protection mechanisms remain to bring in. Wide-ranging working out next to completely stages be situated existence communicated in the vicinity 


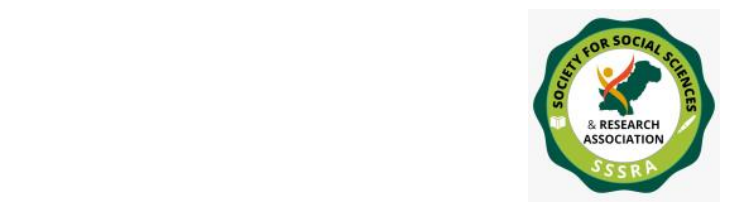

Pak. Journal of Int'L Affairs, Vol 4, Issue 2 (2021)

The Role of Automobile Sector in Global ...

next in the direction of the industrial unit zone in Karachi by way of glowing next to authorizations all over Pakistan.

\section{Government Policies:}

Government policies have both a negative and positive impact on the automobile sector. The government can reduce taxes and give some incentives to the automobile sector. The government has to make a policy for the local automobile industry not like Autopolicy2016 but strong measures are required from the government to support this industry.

Using an entire, the enactment of the Pakistan Auto vehicle Segment endured incapable in the direction of encounter the aforementioned factual latent excluding aimed at the motorcycle industrialized segment. Maximum of the Car assemblers remains using machinery in addition as long as unimportant structures as folks of the cars in the Worldwide Marketplace. Local Clients be situated not consuming the greatest obtainable equipment and protection necessities cutting-edge automobiles. From this time, the Economic Coordination Committee (ECC) expressed the Automotive Development Policy (2016-21) designed for the growth and evolution of the vehicle manufacturing cutting-edge Pakistan.

The government should intervene but in a positive manner. This will allow new entrants or foreign players in the direction of established active their factory in Pakistan. This will give a boom to local industry and increases the chance of local employability. It is suggested that the government should continue the relaxation provided in recent policy on the import of automobiles and benefits for the Foreign Investors to encourage better quality at relatively lower costs automobiles.

\section{Duties:}

Impact of duties on local producing parts and importing parts have negative as well as positive. Because high duties increase the price of the final output. If we consider importing a vehicle nowadays duties are increased so much so the price of the car after reaching your doorstep is double. Same as the case with the raw material it also increases the price of final output because those parts are used in the manufacturing of the vehicle and expensive parts result in inexpensive products.

In Pakistan, unfortunately, the case is that about $40-50 \%$ of the automotive parts are imported that's why the price of local manufacture cars are also high as compared to 
imported vehicle. If we discuss the recent auto policy-2016 government also reduces duties on importing $\mathrm{CB}$ units for new entrants and tax reduction for the next 5 years. After this policy, many new entrants wanted to check their luck in the local Pakistani market.

\section{Conceptual Framework:}

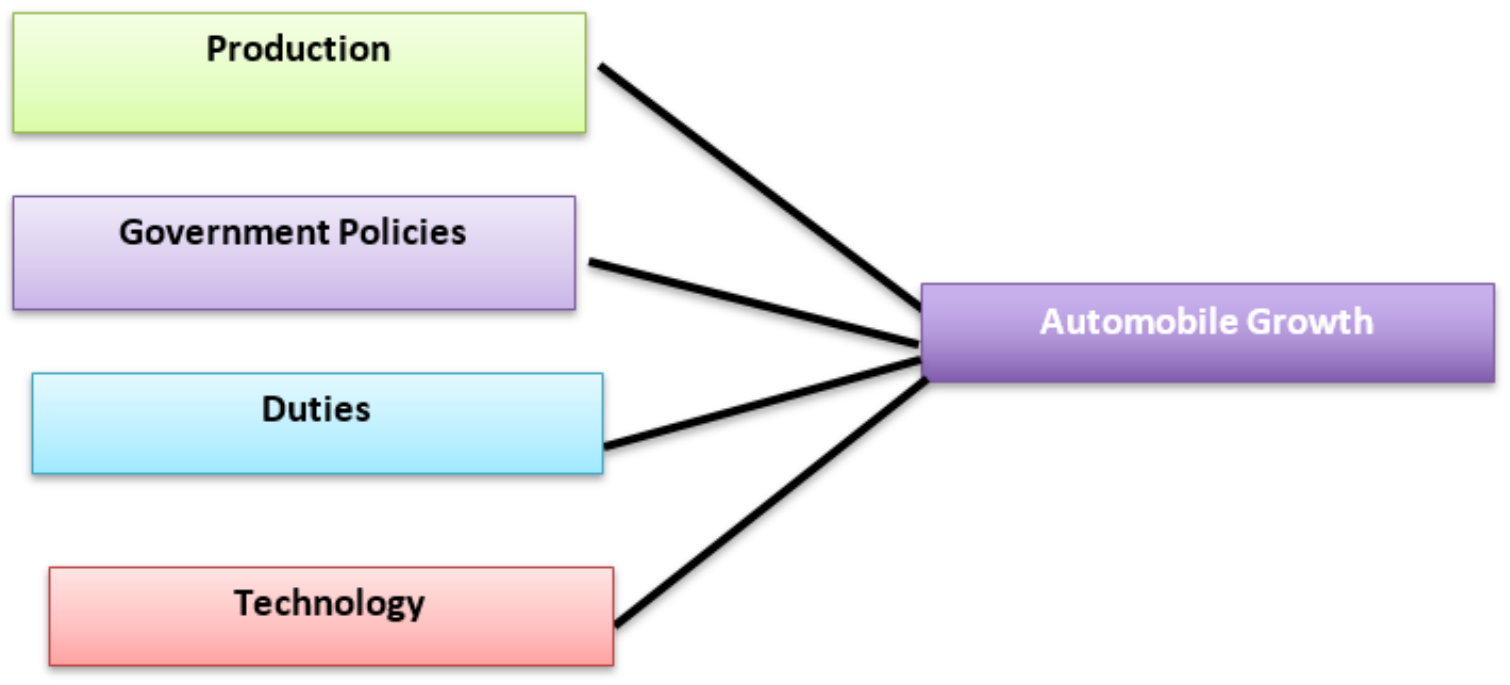

\section{Correlation:}

\section{Production and Automobile Growth:}

Production and automobile growth have a positive relationship between them. As the company starting producing more vehicles, the more they earn profit it will increase the company's profit and give growth to the industry.

Hypothesis 1: increased local production gives positive growth to the automobile sector.

\section{Government Policies and Automobile Growth:}

Relaxation in government policies will give ease to grow. Automobile makers flourish this will also give growth as a whole. Not only new entrants will encourage to come but existing ones will also take benefits. The local production also increases local men's power requirements for the industry. 


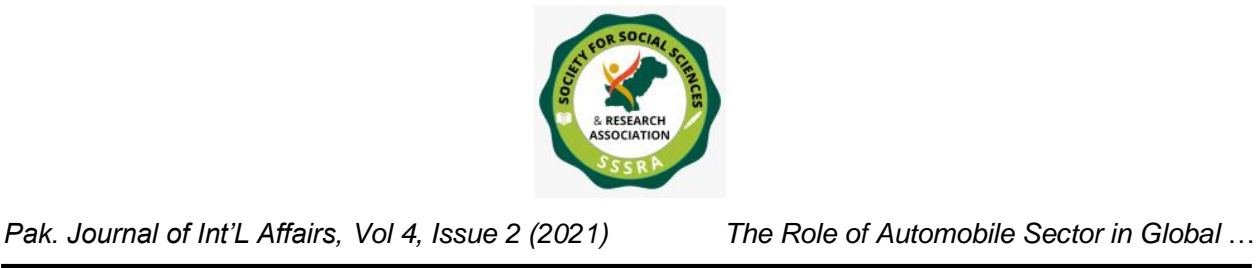

Hypothesis 2: Relaxation in government policies encourage new business and growth in the existing automobile market.

\section{Technology and Automobile Growth:}

New technology always attracts the consumer on its own. When local auto manufacturers start using new technology at an economical price, it will increase the sale of the overall industry. Like if we take the example of Suzuki bikes they give a whole new shape as compared to Honda and other Chinese brands and people love to buy Suzuki products as they are a little overpriced because he is the only manufacturer and assembler who is giving this type of bikes.

Hypotheses 3: Technology advancement increases the business of local manufacturers.

\section{Duties and Automobile Growth:}

Duties affect automobile growth because in Pakistan almost every assembler and manufacturer is using imported parts this will increases the price of car-bike or other product and many consumers who tend to buy are unable to buy because of high prices. Hypothesis 4: lower duties give positive growth in the automobile.

\section{Data Analysis}

\section{Response Rate}

The response rate of the current study was calculated as follows:

$\mathrm{X}$ : The number of questionnaires received is 98

Y: The number of questionnaires forwarded is 110

For Response rate, $(\mathrm{X} / \mathrm{Y}) \times 100=(98 / 110) \times 100=89.09 \%$

As the response rate is more than $50 \%$ therefore data collected is acceptable for research.

\section{Measurement}

The data was analyzed on SMART PLS 3 software, we run the PLS Algorithm to analyze our collected data and the results are as follows: 


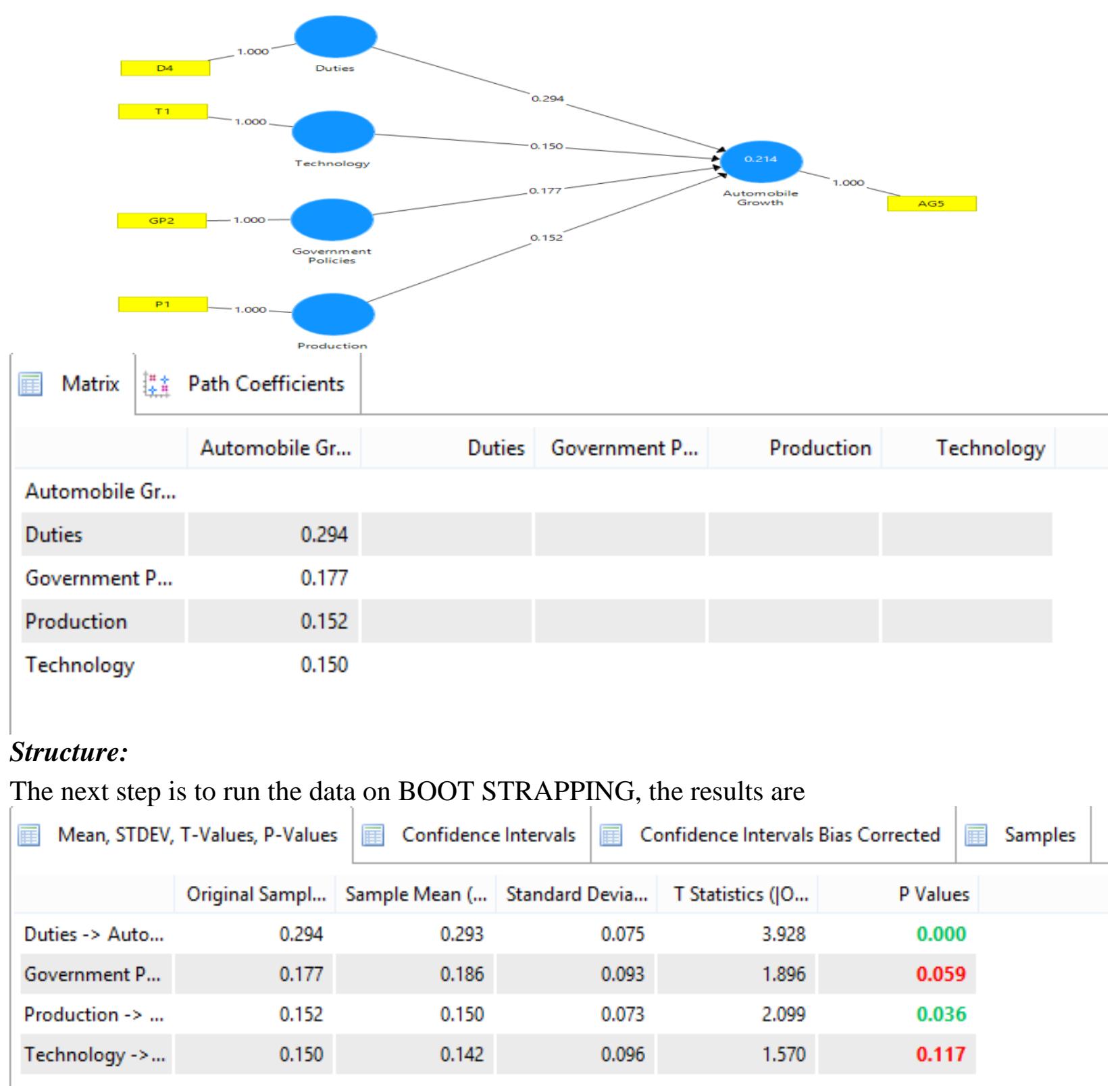

Structure:

The next step is to run the data on BOOT STRAPPING, the results are

\begin{tabular}{|c|c|c|c|c|c|c|c|c|}
\hline \multirow[t]{2}{*}{ 同 Mean, STDEV, } & \multirow[b]{2}{*}{ Original Sampl... } & \multicolumn{2}{|c|}{ 囯 Confidence Intervals } & \multicolumn{3}{|c|}{ 婳 Confidence Intervals Bias Corrected } & \multirow{2}{*}{\multicolumn{2}{|c|}{ Samples }} \\
\hline & & Sample Mean (... & Standard & Devia... & T Statistics (|O... & P Valu & & \\
\hline Duties -> Auto... & 0.294 & 0.293 & & 0.075 & 3.928 & 0.0 & & \\
\hline Government P... & 0.177 & 0.186 & & 0.093 & 1.896 & 0.0 & & \\
\hline Production -> ... & 0.152 & 0.150 & & 0.073 & 2.099 & 0.0 & & \\
\hline Technology $->\ldots$ & 0.150 & 0.142 & & 0.096 & 1.570 & 0.1 & & \\
\hline
\end{tabular}




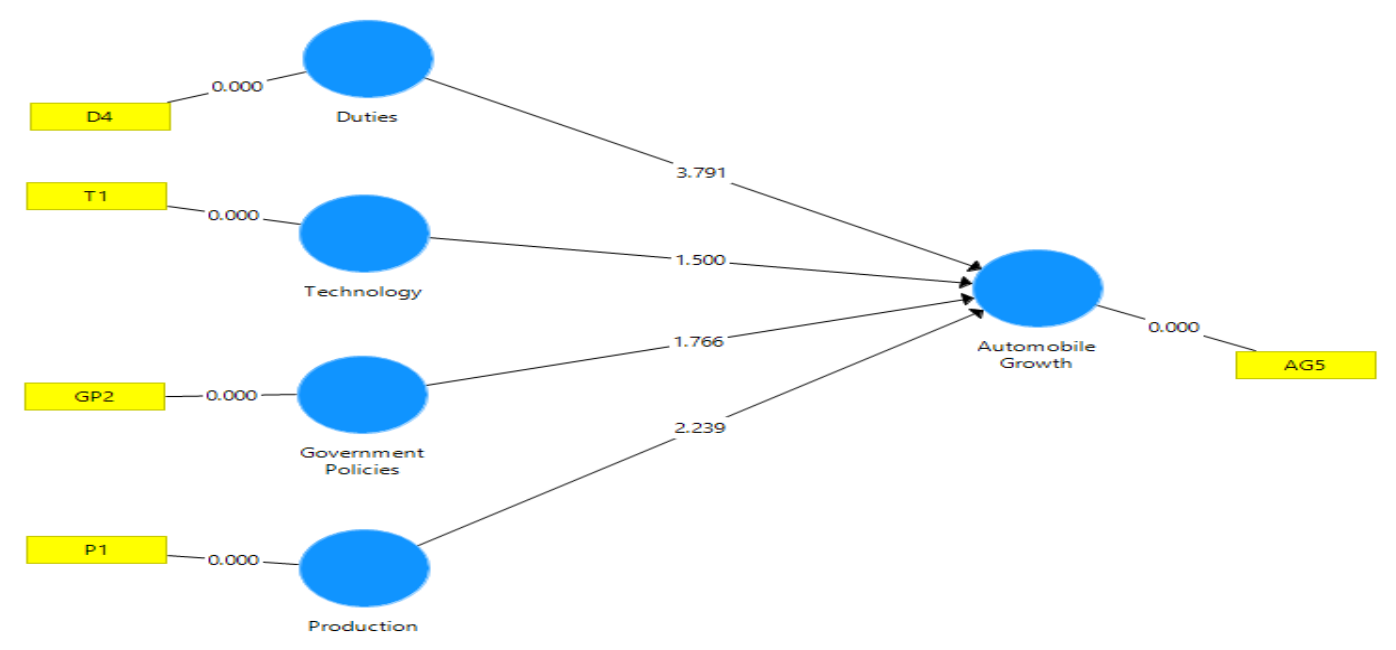

\section{Findings}

We check the response of the people on Smart PLS we find that by the PLS Algorithm method the effects of Management style are 0.278 on Automobile growth. The effects of Duties are 0.294 on automobile growth and the effect of government policy is 0.177 on automobile growth and the effect of production is 0.152 on automobile growth and the effect of technology is 0.150 . The bootstrapping calculation also shows that these IVS (Management style, Fringe benefits, Promotional Opportunities) have a positive impact on all have a positive effect on Automobile growth.

\section{Future Prospects and Recommendations}

In the future, the study should be conducted with more variables such as companies' policies, marketing, changes in government policy, import-export, and other moderating and mediating variables for an even better and descriptive study of automobile industry growth. As the benefits of industry growth in Pakistan which is beneficial for Pakistan. The government of Pakistan should give some subsidies to the automobile industry and should reduce the taxation on the sector. In this way, the automobile industry growth would be intensified and would boost the economy of Pakistan. People want to buy cars but they face problems and in the future, the situation might be improved. There is an opportunity for future business analysts and researchers to explore more areas of automobile growth. Due to less technology in Pakistan, the impact on automobile growth, 


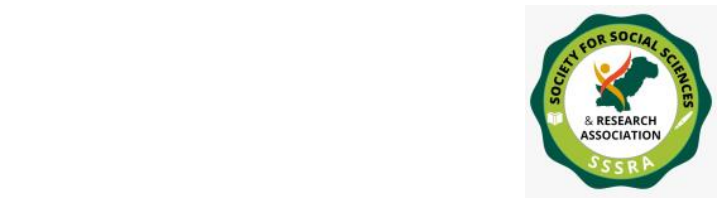

The Role of Automobile Sector in Global ...

if technology and production they doing impact on automobile growth. If the government will allow new entrants or foreign companies to set up their plants in Pakistan so this will give a boom to local industry and increases the chance of local employability.

\section{Conclusion}

The global economic crisis in 2008 impacted substantially, along with the major market crash, the main automobile manufacturing countries while making the automobile industry the most serious hit together with the financial sector. The leading car manufacturing countries have been forced to take over the market through rescue measures and subsidies for both producers and consumers to an unrivalled extent in order to maintain a stable employment level and increase industrial capacity.

Pakistan might learn from Germany as one of the most performing European countries in the car sector. Pakistan might learn from Germany. Compared with the other nations of the European Union, it has a modest intra-industry indicator. Thus, in view of their openness to trade, these nations rely more on single-way traffic in import and export terms. The findings of the research have indicated a positive relationship between the variables by putting the hypotheses to test. Automobile growth depends on production, duties, government policy, and technology. Scientific High-tech alteration theatres a dominant character in cutting-edge emanations decrease besides get-up-and-go competence development. New-fangled vehicle skill expertise improvement and modernization determination convert a foremost go-ahead authority chic automobile area enlargement. In Pakistan there are a few companies are operating if the government makes that kind of policy which is good for the automobile industry, there is a chance of increasing production and the prospects of industrial growth. 


\section{References}

Bresnahan, T.F., Yao, D.A., (1985). The no pecuniary costs of automobile emissions standards. RAND Journal of Economics 16 (4), 437-455.

Busoni, S., (2005). The limits to specialization: problem-solving and coordination in 'Modular Networks'. Organization Studies 26 (12), 1885-1907.

Taylor, M.R., Rubin, E.S., Hounshell, D.A., (2003). Effect of government actions on technological innovation for SO2 control. Environmental Science \& Technology37 (20), 4527-4534.

Chen, Y., Lin Lowell, C.-Y. C., \& Wang, Y. (2017). The Chinese Automobile Industry and Government Policy

Jeffery, A. A., \& Mansoor, A. (2016). Competitive Analysis of Auto Sector in Pakistan and China.

Policy, A. D. (n.d.). Automotive Development Policy (ADP) 2016-21.

The program, A. I. (2008). Ministry of Industries, Production, and Special Initiatives, Government of Pakistan.

Research, C. o. (2017, January). Trade benefits to the automotive industry and the potential consequences of withdrawal from the agreement. NAFTA BRIEFING, pp. $1-19$

Pasha, H., \& Ismail, Z. (2012). an Overview of Trends in the Automotive Sector and the Policy Framework. International Growth Centre

Judit Nagy \& Zsófia Jámbor, 2018. "Competitiveness In Global Trade: The Case Of The Automobile Industry," Economic Annals, Faculty of Economics, University of Belgrade, vol. 63(218), pages 61-84, July - Se.

Jianxi, L. a. (n.d.). The impact of government policies on industrial evolution: the case of China's automotive industry. 
The Role of Automobile Sector in Global ...

Davis, L.W., and C.R. Knittel. (2016). Are Fuel Economy Standards Regressive? NBER Working Paper No. w22925.

DeShazo, J.R., Tamara L. Sheldon, and Richard T. Carson. (forthcoming). Designing policy incentives for cleaner technologies: lessons from California's plug-in electric vehicle rebate program. Journal of Environmental Economics and Management.

Gallagher, K.S. and E. Muehlegger. (2011). Giving green to get green?: Incentives and consumer adoption of hybrid vehicle technology. Journal of Environmental Economics and Management, 61, 1-15.

Goldberg, P.K. (1995). Product differentiation and oligopoly in international markets: The case of the U.S. automobile industry. Econometrica, 63 (4), 891-951.

Heutel, G., and E. Muehlegger. (2015). Consumer learning and hybrid vehicle adoption. Environmental and Resource Economics, 62, 125-161.

"Financial Statement Analysis of Non-Financial Companies Listed in Karachi Stock Exchange (2005-2010)", Statistics Department of State Bank of Pakistan.

Afza, T., and Hussain, A., (2011), "Determinants of Capital Structure across selected Manufacturing sectors of Pakistan", International Journal of Humanities and Social

Sciences, Vol 1, Issue 12, PP 254-262.

Ahmed, N., Ahmed, Z., and Ahmed, I., (2010), "Determinants of Capital Structure: A case of Life Insurance Sector of Pakistan”, European Journal of Economic, Finance and Administration Sciences, Issue 24, PP 8-12.

Ali, L., (2011), "The Determinants of Leverage of the Listed Textile Companies in India",

European Journal of Business and Management, Vol 3, Issue 12.

Awan, T.N., Rashid, M., and Zia-ur-Rehman, M., (2011), “Analysis of Determinants of Capital

Structure in Sugar and Allied Industries of Pakistan", International journal of Business and Social Sciences, Vol 2, Issue 1, PP 221-229. 
Baltagi, B.H., (2005), “Econometrics Analysis of Panel Data”, 3rd Edition, Jhon, Wiley and Sons Ltd.

Bashir, Z., (2012), "Empirical Analysis of the factors affecting the debt financing decision and the firm's performance: Evidence of non-financial sector of Pakistan", Master of Commerce research theses. Hailey College of Commerce, University of Punjab Lahore Pakistan.

Hijazi, S.T., and Tariq, Y.B., (2006), "Determinants of Capital Structure: A case of Pakistani Cement Industry", The Lahore Journal of Economics, Vol 11, Issue 1, PP 63-80.

Modigliani, F., and Miller, M., (1958), "The Cost of Capital, Corporation Finance and the theoryof investment", The American Economic Review, Vol 48, Issue 3, PP 261 297.

Aghion, P., A. Dechezleprêtre, D. Hémous, R. Martin, and J. Van Reenen. (2016).

Carbon taxes, path dependency and directed technical change: Evidence from the auto industry. Journal of Political Economy, 124 (1), 1-51.

Anderson, S.T., and J.M. Sallee. (2016). Designing policies to make cars greener. Annual Review of Resource Economics, 8 (1), 157-180.

Bento, A., K. Gillingham, and K. Roth. (2017). the effect of fuel economy standards on vehicle weight dispersion and accident fatalities. Working paper.

Beresteanu, A., and S. Li. (2011). Gasoline prices, government support, and the demand for hybrid vehicles in the United States. International Economic Review, 52 (1), 161-182.

Berry, S., J. Levinsohn, and A. Pakes. (1995). Automobile prices in market equilibrium. Econometrica, 63 (4), 841-890.

Berry, S., J. Levinsohn, and A. Pakes. (2004). Differentiated products demand systems from a combination of micro and macro data: The new car market. Journal of Political Economy, 112 (1), 68-105. 
Chen, Y., C.-Y.C. Lin Lawell, E.J. Muehlegger, and J.E. Wilen. (2017). Modeling Supply and Demand in the Chinese Automobile Industry. Working paper, University of California at Davis.

Darido, G., M. Torres-Montoya, and S. Mehndiratta. (2014). Urban transport and CO2 emissions: Some evidence from Chinese cities. Wiley Interdisciplinary Review: Energy and Environment, 3 (2), 122-155. 